\title{
The evolution of intergroup tolerance in nonhuman primates and humans
}

\author{
Anne C. Pisor ${ }^{1,2}$ (1) | Martin Surbeck $k^{3,4}$
}

${ }^{1}$ Department of Anthropology, Washington State University, Pullman, Washington

${ }^{2}$ Department of Human Behavior, Ecology, and Culture, Max Planck Institute for Evolutionary Anthropology, Leipzig, Germany

${ }^{3}$ Department of Human Evolutionary Biology, Harvard University, Cambridge, Massachusetts

${ }^{4}$ Department of Primatology, Max Planck Institute for Evolutionary Anthropology, Leipzig, Germany

\section{Correspondence}

Anne C. Pisor, Department of Anthropology, Washington State University, Pullman, WA 99164-4910.

Email: anne.pisor@wsu.edu

\begin{abstract}
Primate individuals use a variety of strategies in intergroup encounters, from aggression to tolerance; however, recent focus on the evolution of either warfare or peace has come at the cost of characterizing this variability. We identify evolutionary advantages that may incentivize tolerance toward extra-group individuals in humans and nonhuman primates, including enhanced benefits in the domains of transfer, mating, and food acquisition. We highlight the role these factors play in the flexibility of gorilla, chimpanzee, bonobo, and human behavior. Given humans have an especially broad range of intergroup behavior, we explore how the human foraging ecology, especially large spatial and temporal fluctuations in resource availability, may have selected for a greater reliance on tolerant between-community relationshipsrelationships reinforced by status acquisition and cultural institutions. We conclude by urging careful, theoretically motivated study of behavioral flexibility in intergroup encounters in humans and the nonhuman great apes.
\end{abstract}

\section{KEYWORDS}

cooperation, hominoids, human evolution, intergroup encounter, primate behavior, sociality, tolerance

\section{1 | INTRODUCTION}

Attempting to explain the prevalence of intergroup aggression in primates, especially in humans (Homo sapiens sapiens), evolutionary anthropologists have focused extensively on intergroup contest and warfare. In response, other evolutionary anthropologists have focused extensively on peace systems in primates, especially in humans. Focusing on these two ends of the spectrum-war or peacefulness-has come at the cost of fully characterizing within-species variation in individuals' behavioral strategies in intergroup encounters (e.g., Refs. 1-4; see also, Ref. 5: table 22-1). Furthermore, both of these approaches emphasize selection pressures that favor or disfavor intergroup aggression; less researched are the selection pressures that, given disincentives for intergroup aggression, favor tolerant encounters and the prolongment of tolerant encounters in intergroup association.
In the present review, our goal is to call for explicit theorization about the individual-level selection pressures that favored flexible behavior in intergroup encounters in humans and nonhuman primates, especially the often-overlooked pressures that may favor tolerant encounters and association given disincentives for aggression. We review how tolerant behavior toward extra-group conspecifics in specific domains-such as food access, mating, and reconnaissance before transfer-may have been favored by natural selection in nonhuman primates. In the course of this review, we pay special attention to the group-living, nonhuman great apes, but not because these species are necessarily the best analogies for intergroup behavior in humans. We focus on these species for two reasons: first, due to our common ancestry, humans and the extant nonhuman great apes share a number of traits derived within the Primate order, suggesting that there is (at least some) insight to be gained by drawing comparisons between these species; and second, to highlight

This is an open access article under the terms of the Creative Commons Attribution-NonCommercial License, which permits use, distribution and reproduction in any medium, provided the original work is properly cited and is not used for commercial purposes.

(C) 2019 The Authors. Evolutionary Anthropology: Issues, News, and Reviews published by Wiley Periodicals, Inc. 
how little we still know about intergroup encounters in the nonhuman great apes, especially in gorillas and bonobos.

Given what has been observed of intergroup behavior in nonhuman primates, we assess whether consideration of the potential selective benefits favoring intergroup encounter and association in these species provides insight into human behavior. Our review of the literature suggests that the particularly high prevalence of intergroup tolerant encounter and association in humans may be derived, even within the great apes; we hypothesize that this high prevalence reflects human reliance on resources that vary extensively in their availability across space and time. Given that our field has invested much energy into studying the selection pressures favoring or disfavoring intergroup aggression, we conclude by urging evolutionary anthropologists to explicitly theorize about individual-level selection pressures that may favor intergroup tolerant encounters, and even prolonged intergroup association, so that we can better understand the variation in intergroup behavior within and between species.

\section{1 | Defining our terms and assumptions}

To discuss tolerance in the context of intergroup encounters, we first define groups, encounters, and tolerance (for brief definitions of the terms used in this article, see Glossary). As commonly defined in the primate behavior literature, groups are individuals "which remain [physically] together in or separate from a larger unit" and interact with each other more than with other individuals in the vicinity. ${ }^{6}$ Because same-group conspecifics are competitors that can negatively affect an individual's reproductive fitness, the selection pressures that may have favored group living across the Primate order are a subject of debate (for reviews of the leading hypotheses, see Refs. 6,7). For group living to persist, the fitness costs related to group living must be outweighed by fitness benefits, for example, predation avoidance. Indirect fitness benefits generated by associating with same-sex kin may further amplify the benefits of group living. In short, despite conflicts of interest between an individual and a conspecific, an individual may remain in association with this conspecific if there are net fitness benefits to doing so.

One of the benefits of living in a group, which can also be a benefit of association between groups, is resource defense against conspecifics. If a resource is economically defensible-that is, if an individual stands to gain net fitness benefits from defending it-the individual may coordinate with others in their group to exclude third parties from the area of the group's range where the resource is located. ${ }^{8}$ Whether a resource is economically defensible by an individual or individuals is a product of its characteristics, such as its distribution, density, size, and predictability ${ }^{9}$; the individual's demand for the resource (e.g., her frequency of us $\mathrm{e}^{10}$ ), as well as the demand of third parties (e.g., as a consequence of population density ${ }^{11}$ ); and the individual's caloric or nutritional requirements. The degree of home range overlap between two neighboring groups, especially the frequency with which areas of range overlap are used, can indicate that relevant resources are less economically defensible and thus that there are diminished incentives for intergroup aggression-at least at the edges of a group's home range. As such, range overlap is sometimes employed as a first-pass approximation of opportunities for intergroup encounter. ${ }^{10}$ However, while opportunity for encounter is a prerequisite for encounters, it does not provide insight into incentives for encounter; we focus on the latter here.

When conspecifics from two different groups are in visual or vocal contact with one another, they are involved in what we term an intergroup encounter (although there are notable limitations to relying on vocal encounter data; see the Glossary for further discussion). If conspecifics remain in visual or vocal contact without aggressing against one another, they are exhibiting tolerance (cf. Ref. 2). We evaluate selection pressures that may favor intergroup tolerant encounters, or even prolonged intergroup association, over the course of this review.

To generate hypotheses about the relevant benefits and costs of different kinds of intergroup behavior, it is useful to begin by assuming that individual behavior is flexible and reflects an optimal response to socioecological conditions. ${ }^{3,12}$ By this logic, natural selection should favor features of primate psychology that are sensitive to the net benefits of association with conspecifics in the current ecological and social context, ${ }^{3}$ modulating tolerant and aggressive behavior accordingly. Of course, a socioecological approach cannot explain all behavioral variation; factors affecting the social strategies available to an individual include phylogenetic inheritance, life history trade-offs, and collective action problems. ${ }^{13-15}$ It does, however, allow initial theorizing about the underlying selective forces shaping the variety of intergroup behavior observed both within and between primate species.

\section{2 | From disincentives for aggression to incentives for tolerance}

Individual behavior in intergroup encounters is flexible, following a continuum from aggressive to tolerant, and this flexibility reflects the local environment (e.g., the patchiness of resources, seasonality in resource availability, species' diet breadth), the qualities and condition of the interacting individuals (e.g., sex, resource access, rank, the reproductive status of each), and features of the interacting groups (e.g., the balance of power between the two, the presence and number of estrous females in one or the other). However, despite evidence of this behavioral flexibility, much of the existing literature on intergroup behavior in primates emphasizes the release of selection pressures favoring aggression (e.g., the Dear Enemy Effect ${ }^{16}$ ), which allows for either "random"17 or tolerant encounters (Figure 1); for example, other reviews have provided thorough treatment of the selection pressures favoring (or disfavoring) aggressive intergroup behavior in nonhuman primates and in humans. ${ }^{3,5,15,18}$ Our approach differs in that we focus on individual-level selection pressures that, given selection pressures disfavoring intergroup aggression, favor intergroup encounter and association over random encounter. When incentives for contest with extragroup conspecifics are low, optimality theory would predict that (a) if there are low benefits to encounter, an individual should randomly encounter extra-group conspecifics ${ }^{17}$ (d, Figure 1) and (b) if there are high benefits to encounter, an individual should encounter extra-group conspecifics at a rate higher than chance (b, Figure 1). If individuals gain net benefits from intergroup encounters, these encounters should be 
positively favored by selection to increase in duration and to recur-to become intergroup associations.

The evolution of multilevel societies likely hinged on high net benefits to intergroup tolerant encounter ${ }^{19-21}$; theoretical work on the evolution of multilevel societies can inform our understanding of why natural selection may have favored flexible tolerance toward extragroup members at the individual level. For example, Kirkpatrick and Grueter ${ }^{19}$ considered how, given reduced incentives for aggression due

\section{Contest incentives}

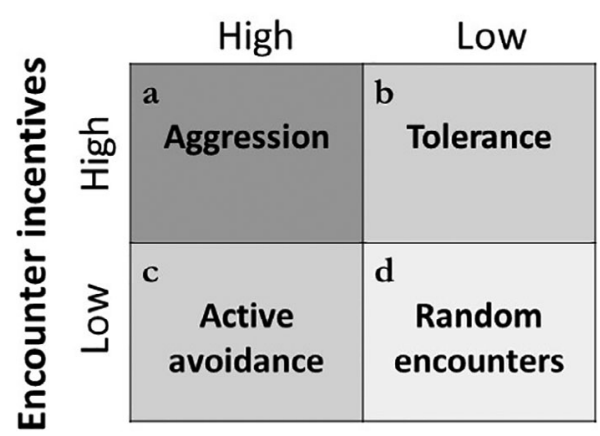

FIGURE 1 Basic incentive structure for behavior toward an extragroup conspecific. Contest incentives include the net benefits of defending food resources or mates, among others. Incentives for encounter include the net benefits of enhanced food acquisition, predation avoidance, and opportunities for mating and transfer to food abundance, defending females against extra-group males may have favored extended association in golden snub-nosed monkeys (Rhinopithecus roxellana). Likewise, Schreier and Swedell ${ }^{20}$ discussed both disincentives for aggression and incentives for extended association in Hamadryas baboons (Papio hamadryas hamadryas), attributing the former to food abundance and the latter to predation avoidance. Below, we draw on the threads of this literature to organize observations of intergroup encounters in nonhuman primate species with respect to potential selection pressures that may incentivize these encounters.

\section{2 | INTERGROUP TOLERANT ENCOUNTERS AND ASSOCIATION IN NONHUMAN PRIMATES}

Drawing on the socioecological approach, theoretical perspectives on the evolution of multilevel societies, and existing hypotheses put forward by field researchers, we have compiled a list of benefits to intergroup tolerant encounter in Table 1, highlighting how these benefits are typically realized. Note that the first three of these candidate benefits are likewise benefits that may have favored group living; selection pressures favoring association with conspecifics within groups can extend to association with conspecifics between groups. In a nonexhaustive list in Column 3, we identify nonhuman primate species in which observations of intergroup interactions are consistent with a given benefit. Assuming benefits from intergroup interactions can be

TABLE 1 Potential benefits to tolerant intergroup encounter and association

\section{Benefits of tolerant intergroup encounter \\ Increased resource-holding potential \\ Association with extra-group individuals permits: \\ Actively or passively deterring third-party extra-group members from accessing a contested resource $(\mathrm{m} / \mathrm{f})^{\mathrm{a}}$ \\ Passively defending mating partners against third-party extra-group members ( $m$ high)}

Enhanced foraging returns

Reduced predation risk

Reduced predation risk

Reconnaissance before transfer

Extra-group mating
Knowing which resource patches have been depleted by conspecifics $(\mathrm{m} / \mathrm{f})$

Learning the location of food or methods of food extraction $(\mathrm{m} / \mathrm{f})$

Enhancing vigilance and diluting the per-capita risk of predation $(\mathrm{m} / \mathrm{f})$

Gaining information about groups to which individuals might transfer ${ }^{15}$ (m/f low)

\section{Nonhuman primate examples}

Tamarins (genus Sanguinus) ${ }^{22} *$

Baboons (genus Papio) ${ }^{23}$

Golden snub-nosed monkeys (Rhinopithecus roxellana $)^{19}$

Yunnan snub-nosed monkeys (Rhinopithecus bieti) ${ }^{24}$

Tamarins (genus Sanguinus) ${ }^{25}$

Hamadryas baboons (Papio hamadryas hamadryas) ${ }^{20}$
Ring-tailed lemurs (Lemur catta) ${ }^{26}$
Vervets (Cercopithecus aethiops) ${ }^{27}$
Chimpanzees (Pan troglodytes) ${ }^{28}$
Bonobos (Pan paniscus) ${ }^{29}$
Gorillas (Gorilla gorilla, beringei) ${ }^{30,31}$
Ring-tailed lemurs (Lemur catta) ${ }^{26}$
Bonobos (Pan paniscus; mixed evidence ${ }^{32}$ )
Chimpanzees (Pan troglodytes) ${ }^{28}$

In the second column, we identify how these benefits are typically realized; where benefits are more likely to accrue to individuals of a given sex or rank, we note this in parentheses (" $m$ " for male, "f" for female, "high" for high rank, "low" for low rank). In the third column, we provide a nonexhaustive list of primate species in which interactions consistent with the hypothesized benefit have been observed. Nonhuman great ape species are highlighted in bold font. One set of observations of interspecific intergroup encounters, rather than intraspecific (as are the focus of this paper), is indicated with an asterisk $(*)$. Where relevant, we cite existing reviews providing further details on how benefits can be realized.

${ }^{a}$ Resource defense can be passive, consisting solely of a numerical advantage over other groups or associations of groups, or active, if groups in association aggress against third parties that threaten to displace them. ${ }^{2}$ 
reliably obtained, intergroup encounter and association may be favored by natural selection - for example, as was the case in the evolution of multilevel societies.

Two mechanisms can further enhance the net benefits of intergroup encounter and association. First, the net benefits of interacting with extra-group members may be higher if these individuals are relatives, as these interactions can have positive effects on inclusive fitness. ${ }^{15}$ Such kinship connections across groups arise due to past group fissioning and individual transfer. Furthermore, there may be inclusive fitness benefits for adults if they tolerate subadult contact between groups when their adolescent offspring are nearing transfer. ${ }^{33}$ Second, partner preferences across groups can help to enhance the net benefits of intergroup encounters. For example, individuals appear to draw on memories of past experiences with specific extra-group members to anticipate their behavior, ${ }^{27}$ selectively approaching individuals likely to be tolerant and avoiding those likely to be aggressive. ${ }^{15}$

Of the five benefits we identify on Table 1, existing observations of the nonhuman great apes are consistent with only two. This is not for lack of intergroup tolerant encounters: while orangutans (genus Pongo) do not live in groups, making the question of intergroup encounters moot, intergroup encounters have been observed in chimpanzees (Pan troglodytes), bonobos (Pan paniscus), and gorillas (Gorilla gorilla and Gorilla beringei; Figure 2). Despite the presence of intergroup encounters in all four species, we know vastly more about intergroup encounters in chimpanzees than bonobos or gorillas.

This disparity in research effort is predominantly attributable to the use of chimpanzee intergroup behavior as a referential model for human intergroup behavior. Jane Goodall's observations of intergroup aggression in chimpanzees at Gombe National Park inspired a generation of primatologists to further research the topic (see Ref. 34 for a review), contributing to chimpanzees' status as one of the most studied nonhuman primates. Given the relatedness between chimpanzees and humans, this literature often asserts that chimpanzees provide an analogy for humans-namely, that chimpanzees' social behavior should approximate that of the last common ancestor shared by chimpanzees and humans, giving scientists insight into the evolutionary roots of human intergroup violence. ${ }^{35}$ Along this vein, some suggest that fission into male-male parties, as seen in chimpanzees, supported intergroup warfare in early Homo (see Ref. 36 for discussion). Although there is debate over whether chimpanzee social systems offer a useful analogy for human behavior, ${ }^{35,37}$ this debate tends to assess the fine-grained details of chimpanzees as a referential model rather than to explore whether other species may provide analogies for, and thus insight into, human behavior.
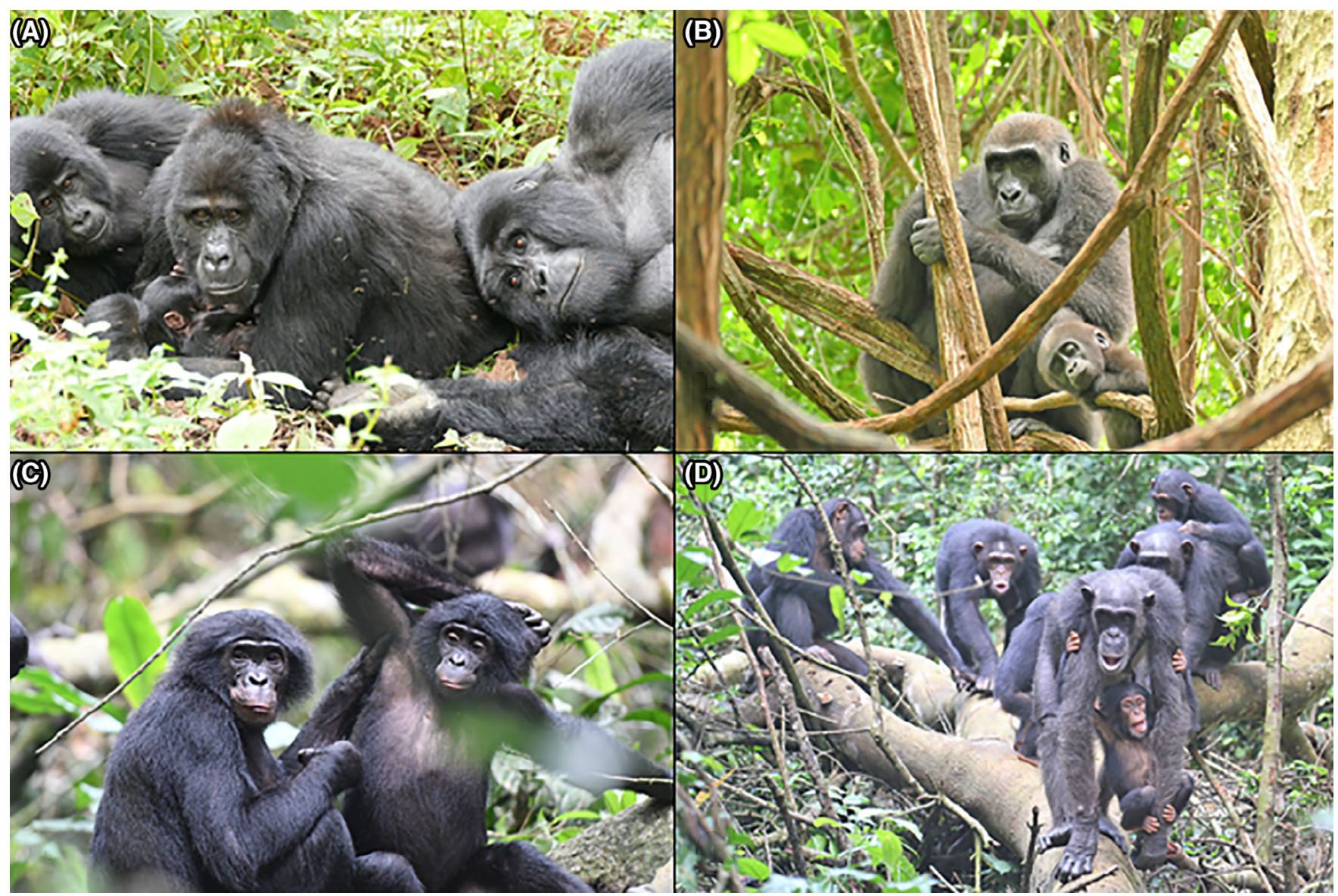

FIGURE 2 (a) Mountain gorillas (Gorilla beringei). (b) Western gorillas (Gorilla gorilla). (c) Bonobos (Pan paniscus). (d) Chimpanzees (Pan troglodytes) (a and b) Courtesy of Martha M. Robbins/Max Planck Institute for Evolutionary Anthropology. (c) Courtesy of Martin Surbeck/Kokolopori Bonobo Research Project. (d) Courtesy of Liran Samuni/Taï Chimpanzee Project [Color figure can be viewed at wileyonlinelibrary.com] 
Consideration of other species, including nonhuman primates and even invertebrates that underwent convergent evolution, suggests that anthropologists' heavy reliance on chimpanzee intergroup encounters as a referential model is short-sighted. The possibilities that human ancestors exhibited fission-fusion dynamics and lived in multilevel societies are not in direct opposition ${ }^{21,36}$; as such, a number of extant primate groups that live in multilevel societies with fission-fusion dynamics (e.g., Rhinopithecus species, Hamadryas baboons) offer insight into the evolution of human social systems. ${ }^{21}$ Looking to invertebrates, polydomous ants provide a potential analogy for identity maintenance despite between-group cooperation in humans. ${ }^{2}$ Furthermore, the nonhuman great apes remain a source of insight, even if scientists disagree about the relevance of chimpanzee social systems for understanding human intergroup behavior. Bonobos, for example, are as closely related to humans as are chimpanzees. Bonobos have been described as largely peaceful ${ }^{38}$; in reality, however, bonobo intergroup encounters feature both tolerant and aggressive behavior, ${ }^{32}$ and the predictors of these different behaviors may provide insight into the flexibility of human intergroup behavior. Though not as closely related to humans, gorillas likewise exhibit a range of intergroup behavior with clear differences by sex and rank. (See Box 1 for further details on intergroup behavior in these species.) In short, there are many candidate referential models that might provide insight into the evolution of flexible intergroup behavior in humans, and useful analogies need not all be found in the same species or even in the same clade.

Below, we assess the extent to which the selection pressures potentially favoring intergroup encounters in the nonhuman primates, detailed in Table 1 and Box 1, can explain the flexibility and prevalence of intergroup tolerant behavior in humans-or whether additional explanations are needed.

\section{3 | HUMANS IN PRIMATE CONTEXT: PREDICTING INTERCOMMUNITY TOLERANT ENCOUNTERS AND ASSOCIATION}

Humans have social networks on scales unseen in nonhuman primates, ${ }^{39,40}$ networks that often span group boundaries ${ }^{1,2,41,42}$ suggesting that incentives for association with extra-group members must (at least sometimes) be high. To what extent may the domains highlighted in Table 1 account for the flexibility and high prevalence of intergroup tolerance observed in extant humans? We first briefly examine whether these domains predict contemporary human behavior-in both subsistence-scale and post-industrial societies-as documented in the social science literature. Second, we ask whether additional selection pressures may have acted on the human lineage, favoring a high prevalence of intergroup tolerant encounters and association. As have a handful of behavioral ecologists ${ }^{43-46}$ and archaeologists before us, ${ }^{47-52}$ we highlight the relevance of nonlocal resource access and the risk of resource shortfall in incentivizing intergroup tolerant encounters and association in humans; we build on previous theorizing on the subject by addressing why the human foraging ecology involves more risk of resource shortfall and reliance on nonlocal resources than other primate foraging ecologies. Finally, we examine how the accrual of status through intergroup connections and how cultural institutions may support and reinforce resource flows through between-group relationships.

To avoid misunderstanding, let us first clarify the use of the words "group" and "community" with respect to humans. The word "group" has many connotations in the social science literature, ranging from ethnolinguistic groups to gender-based groups to groups formed in experimental contexts (for a discussion, see Ref. 53). Some of these groups are separated in geographic space; others are not. Because we are interested in interactions between conspecifics across space, we frame our review of the human literature in terms of "communities," as Rodseth and colleagues ${ }^{54}$ use the term (see Glossary).

\section{1 | Continuity: Primate-general patterns observed in humans}

\subsection{1 | Resource-holding potential and enhanced foraging returns}

Like other primate diets, human diets often include foods that are both economically defensible and foods that are not. As is true of other group-living apes (e.g., western gorillas), when resources are seasonally abundant and not defensible, these resources can provide the basis for the intermingling of human communities, ${ }^{44}$ including in market contexts $^{55}$ and, as Brewer and Caporael joke, ${ }^{53}$ at scientific conferences. Furthermore, individuals may have increased incentive to associate with extra-community members when they can acquire social information that is potentially useful in the local environment, enhancing returns to foraging and food production; social learning has been especially important in humans, both for foragers ${ }^{48,56}$ and in other societies, ${ }^{56}$ given the diversity of environments we inhabit. However, though intergroup association for resource defense has only been observed in interspecific associations in nonhuman primates (Table 1), human individuals in subsistence-scale and even postindustrial societies sometimes associate with extra-community members to defend a food resource against third-party communities, either passively or in active, collective defense (see Ref. 44 for subsistence-scale examples). In this vein, research from disciplines such as political science and psychology demonstrates that perceived national-level resource threat-sometimes in interaction with other variables-can be correlated with a feeling of common identity with co-nationals from other regions of the country and with increased preferences to exclude immigrants. ${ }^{57}$

Men may maintain relationships across community boundaries to defend females against third-party communities, as has been observed among the Yanomamö. ${ }^{58}$ However, the ethnographic literature suggests that between-community association to defend women is rare: for example, when women are captured from other communities (e.g., bride capture, wife stealing), if revenge or recapture occurs, usually only a woman's family or community are involved (see Ref. 59 for some relevant examples). This is similar to the nonhuman great apes, which likewise show no evidence of female defense through intercommunity association. 


\section{BOX 1 Intergroup tolerant encounter and association in nonhuman great apes}

Though chimpanzees are more often used as a referential model for human intergroup behavior, chimpanzees and bonobos are equally related to humans. Both species live in social groups characterized by fission-fusion dynamics. While both species are also male philopatric (i.e., at maturity, males remain in their natal group and females transfer to other groups), male bonobos do transfer on rare occasions ${ }^{87}$; nevertheless, the genetic differentiation between males of different groups is comparable between the two species. ${ }^{88}$ However, while the majority of intergroup encounters in chimpanzees are hostile (see Ref. 28 for exceptions), bonobo intergroup behavior varies extensively, even within the same individual in the same intergroup encounter (Box Table 1). What predicts when tolerant intergroup encounters occur in bonobos? Recent studies find that prolonged encounters between bonobo groups occur more frequently during times of high fruit abundance, indicating that reduced feeding competition may be a precondition for these encounters. ${ }^{32,89}$ However, as identified in Section 1.1, such findings address only disincentives for aggression (see Figure 1); at this stage, we can merely speculate on the actual incentives to meet. Here are some of the candidate benefits (per Table 1) favoring intergroup encounter in bonobos, given existing observational data:

- Enhanced foraging returns. New data indicate that bonobo groups may remain in prolonged association when at least one of the two is foraging in a less familiar area, suggesting that intergroup association might enhance foraging efficiency and opportunities to socially learn the location of ripe food. ${ }^{89}$ There is also evidence of food sharing between bonobo groups. ${ }^{90}$

- Extra-group mating. During encounters, both males and females will initiate matings with extra-group members; however, the function of these matings is unclear as they rarely result in paternities. ${ }^{32,91}$

- Reconnaissance before transfer. Encounters are used by young females to transfer between groups; however, these females are unlikely to be responsible for initiating intergroup encounters given their limited influence on group movements. ${ }^{92}$ Although not strongly emphasized in the literature on chimpanzee intergroup encounters, female chimpanzees have also been observed to visit other chimpanzee groups, presumably in preparation for transfer. ${ }^{28}$

Box Table 1. Reported differences in intergroup behavior in the group-living nonhuman great ape species

\begin{tabular}{|c|c|c|c|}
\hline & Chimpanzees & Bonobos & Gorillas \\
\hline Home range overlap ${ }^{a}$ & $7 \%-13 \% 97$ & $9 \%-23 \%{ }^{98}$ & $\begin{array}{l}\text { WG: } 27 \%{ }^{99} \\
\text { MG: } 13 \%-100 \%{ }^{95}\end{array}$ \\
\hline Encounter duration & $\begin{array}{l}\text { Hours (single females with } \\
\text { offspring may stay longer) }\end{array}$ & Up to several days ${ }^{89}$ & Up to several days ${ }^{31}$ \\
\hline Occurrence of encounters (\% of observation days) & $3.33 \%-5 \%^{28}$ & $0.2 \%-30 \%^{32,89,90}$ & WG: $2 \%{ }^{99}$ \\
\hline Lethal outcomes & Occur $^{100}$ & Not reported ${ }^{100}$ & $\begin{array}{l}\text { WG: not reported } \\
\text { MG: occur }{ }^{101}\end{array}$ \\
\hline Patrolling and other territorial behavior & Occur $^{102}$ & Not reported & Not reported \\
\hline Coalitions formed among members of the same group & Occur $^{102}$ & Occur $^{b}$ & $\begin{array}{l}\text { WG: not reported } \\
\text { MG: occur }{ }^{101}\end{array}$ \\
\hline Coalitions formed among members of different groups & Not reported & Occur $^{103}$ & Not reported \\
\hline Copulation between groups & Occur $^{28}$ & Occur ${ }^{104}$ & Not reported \\
\hline Food sharing between groups & Not reported & Occur 90 & Not reported \\
\hline Grooming between groups & $\begin{array}{l}\text { Not reported (except in the } \\
\text { case of female visits }{ }^{28} \text { ) }\end{array}$ & Occur ${ }^{104}$ & Not reported \\
\hline
\end{tabular}

WG indicates western gorillas; MG indicates mountain gorillas.

${ }^{a}$ See Section 1.1 for details on the limitations of this measure.

${ }^{\mathrm{b}}$ Personal observation by M.S.

It is possible, per Section 2, that close kinship between females in different bonobo groups facilitates tolerant encounter; however, we do not have the genetic data to evaluate this possibility. In general, to better assess the relevance of bonobo intergroup behavior as a referential model for that of humans-as well as to better understand why bonobo intergroup behavior differs so much from that of chimpanzees, despite their close relatedness and similar social structure-more data are needed. Bonobos have a smaller population size than chimpanzees and are located at sites often inaccessible due to political constraints, hurdles to studying this species. Targeted data collection among these sometimes hard-to-reach populations, further facilitated by habituation of neighboring groups such that encounters can be documented from multiple vantage points, will better elucidate the factors influencing bonobo intergroup behavior. 
Although researchers tend to focus on our closest relatives, chimpanzees and bonobos, as analogies for human sociality, gorillas are also great ape species that may provide insight into the evolution of tolerant intergroup behavior in humans. Although western gorillas tend to be more tolerant toward extra-group members than are mountain gorillas ${ }^{30}$ (Box Table 1), peaceful interactions such as play or touching behavior also occur between members of different mountain gorilla groups. ${ }^{93}$ In western gorillas, mutual attraction to mineral-rich forest clearings may disincentivize aggression ${ }^{94}$-though, as noted above, this observation does not provide insight into incentives for tolerant encounter. Reconnaissance before transfer is one possible benefit to tolerant intergroup encounter in gorillas: like bonobos and chimpanzees, western gorilla females may visit other groups before transfer. ${ }^{30}$ Additionally, males may also benefit from reconnaissance with respect to assessing the competitive abilities of future rivals. ${ }^{30}$ Relatedness or familiarity between male silverbacks in neighboring groups may further enhance the net benefits of tolerant interactions between these individuals ${ }^{95}$ (but see Ref. 96). A recent study on mountain gorillas suggests that tolerant intergroup encounters might be more frequent than previously appreciated, highlighting the relevance of gorilla social structure beyond the group level. ${ }^{93} \mathrm{New}$ data such as these will permit researchers to better assess the extent to which intergroup behavior in the great apes can provide analogies for human tolerant intergroup behavior.

\subsection{2 | Transfer and mating}

Women and men engage in visitation ${ }^{60}$ and sometimes in matings ${ }^{61}$ with members of different communities. Both in subsistence-scale ${ }^{61}$ and post-industrial ${ }^{62}$ societies, visitation permits individuals to try out a prospective community before emigrating. The increased distances at which individuals can visit or make contact today, as fostered by airplane travel and global communications networks, may also act to equalize cooperative preferences with respect to members of different communities, ${ }^{63}$ allowing for additional transfer opportunities. Mate search very often crosses community boundaries, as evidenced by the ethnographic literature ${ }^{64}$ and bolstered by a decades-old literature on heterogamy across space and ethnolinguistic and religious boundaries in economics, sociology, and demography. ${ }^{65}$ In ethnographically-studied societies, men-especially young, unmarried men, as observed among the Agta-are especially likely to travel to and visit at greater distances. ${ }^{64}$ Indeed, in societies where men have higher variance in reproductive success than women, men may attain more mates by visiting distant locations. ${ }^{61}$

\subsection{3 | Kin selection and partner preferences}

As is the case in nonhuman primates, preferential interaction with kin and partner preferences can enhance the net benefits of intergroup encounter in humans. Kin recognition permits individuals to modulate their behavior toward kin or likely kin (e.g., the child of a dispersed sister) in other communities. Furthermore, humans have additional means to reap inclusive fitness benefits through interactions with extracommunity members. Exogamy (marrying outside the community), paired with long-term pair bonding and between-community visitation, enables the recognition of affinal kin (kin by marriage) and the application of kinship terms, and the norms of behavior associated with these terms, to affinal kin. ${ }^{40,50}$ Frequent interaction with affinal kin can enhance an individual's tolerant behavior toward members of their affines' communities, discouraging aggression or free-riding against these individuals and facilitating investment in inclusive fitness interests (e.g., nieces and nephews) across community boundaries. ${ }^{39,40,54,58}$
Partner choice likewise enhances the net benefits of intercommunity tolerant encounter and association in humans. An individual's expectations about extra-community members are often informed by a combination of socially-transmitted information, including information about extra-community members' aggressive behavior during past generations, as well as an individual's own past experiences with extra-community members. ${ }^{4}$ Repeated interactions, like those that take place in markets, can enable strangers from different communities to transition to relationships based on trust and reciprocity that generate greater benefits for the individuals involved. ${ }^{55}$

\subsection{Humans the derived: Human-unique predictors of intercommunity tolerant encounters and association}

The preponderance of between-community relationships in humans suggest that humans are an outlier in the Primate order with respect to our intergroup behavior, even relative to more distantly related primates that, like humans, live in multilevel societies. ${ }^{21}$ As is true for nonhuman primates, resources that are not defensible disincentivize aggression in humans; however, humans may even refrain from engaging in contest over an economically defensible resource in order to maintain betweencommunity relationships. ${ }^{43-45,58}$ Humans will even live in home ranges in which needed or desired resources cannot be obtained, instead relying on between-community relationships for access ${ }^{39}$-something not seen in nonhuman primates. This raises the question: How did humans come to be such an outlier in the Primate order? Evidence suggests that unique features of the human foraging ecology-our reliance on resources that vary extensively in their spatial and temporal availability-may provide part of the answer. The fact that individuals who move resources between communities, ${ }^{48}$ like big men among "complex" hunter-gatherer societies, ${ }^{66}$ are accorded status in their home communities underscores the importance of extra-community resource access; likewise, crosscultural data suggest that when between-community relationships generate individual-level benefits, cultural institutions may further support and reinforce these relationships, amplifying their benefits. 


\subsection{1 | Buffering shortfalls and accessing nonlocal resources}

In the early 20th century, functionalist anthropologists theorized about the importance of between-community relationships for maintaining nonlocal resource access. These authors often leaned heavily on the functions of cultural institutions but did not fail to attend to individual-level benefits of participating in them. For example, Malinowski ${ }^{67}$ proposed that the exchange of ritual goods between islands in the Trobriand Islands, goods to which individuals ascribed great importance, enabled the exchange of resources that they needed or desired for daily life. Radcliffe-Brown ${ }^{68}$ likewise noted that ritualized exchange with other communities permitted individual Andaman Islanders access to valued nonlocal goods. The individuallevel benefits accrued via between-community relationships were later explicitly considered by human behavioral ecologists ${ }^{43-46}$ and archaeologists $^{47-52}$ (see especially Refs. 50,52). Under these theoretical approaches, the importance of managing resource access, including buffering the risk of resource shortfalls and ensuring access to resources never locally available, provides incentives for individuals to build and maintain relationships spanning distance. However, why access to distant resources might be especially important to extant humans relative to other organisms-even relative to the group-living nonhuman apes-was often left unstated.

Although between-community interactions in the group-living nonhuman apes are understudied (see Box 1 and Section 2), initial evidence suggests that the importance of between-community risk management and nonlocal resource access in humans reflects humanspecific adaptations. ${ }^{1}$ In general, primates tend to rely on high-quality, high-risk foods ${ }^{14}$; however, humans' high energy throughput, as related to the cost of our large brains (which themselves may be an adaptation to our foraging ecology ${ }^{69}$ ) and our high reproductive rates, created secondary selection pressures on the effective management of the risk of resource shortfalls. ${ }^{14,70,71}$ The importance of specific, sometimes difficult-to-acquire nutrients for the human brain, ${ }^{72}$ such as foods high in omega-3 fatty acids (see Ref. 73 for a discussion), likely amplified the importance of access to nonlocal resources.

One reason these foods and nutrients are risky and difficult to acquire for humans is that they vary across space and time. In some ecologies, there is more asynchrony in resource acquisition across space ${ }^{44,45}$-that is, in the geographic scope of resource shortfalls. ${ }^{50}$ For example, water availability can be asynchronous across distances of tens of kilometers in southwestern Africa ${ }^{46}$ such that betweencommunity relationships become important sources of water access in cases of local drought. ${ }^{43,46}$ When shortfalls are especially large in spatial scale-for example, in the case of regional drought-betweencommunity relationships may span hundreds of kilometers, as was the case for Aboriginal populations facing drought in Australia in the 1960 s. $^{74}$ However, the frequency of these shortfalls also matters. The more frequent the shortfalls, the more individuals may strategically utilize between-community relationships to maintain access to nonlocal resources, as evidenced by both within- and between-society variation in the importance of these relationships. ${ }^{43-45,47,51,52,75}$ When shortfalls have a large spatial scale but are rare, individuals may not maintain extra-community risk buffering networks but instead use alternative strategies, including migration, opting out of their existing, local buffering networks, or raiding neighboring communities. ${ }^{48,50,52,75,76}$ In short, if shortfalls in the availability of a crucial resource occur at a spatial scale greater than the size of a community and frequently enough that the possibility of their occurrence remains salient, between-community relationships may be an important component of individuals' riskbuffering strategies.

Some resources important in a given ecology may not necessarily fluctuate in their availability, but instead may never be available within a community's home range. ${ }^{52}$ For example, preferred materials for toolmaking ${ }^{39}$ and pottery, ${ }^{68,77}$ medicines, ${ }^{77}$ and salt may never be available locally (Figure 3; see Ref. 78 for a relevant review). Socially-transmitted information relevant to the local ecology may have similar distributional features: extra-community individuals may be sources of information about resource availability, ${ }^{48}$ alternative methods of resource acquisition and extraction, ${ }^{56}$ and, in societies with wage labor, even the availability of jobs. ${ }^{79}$ When important resources, be they physical or informational, cannot be obtained within the local community, between-community relationships may be important for ensuring access. However, it should be noted that between-community relationships do not imply a complete absence of between-community aggression; on the contrary, individuals may only be able to invest in and draw upon these relationships during seasonal ${ }^{77}$ or periodic ${ }^{4}$ peacetimes.

\subsection{2 | Achieving status through between-community relationships}

Data suggest that when nonlocal resource access was important in human history and prehistory, attribution of status-analogous to rank in nonhuman primates, although often earned through prestige rather than dominance ${ }^{80}$-to well-connected individuals supported betweencommunity resource flows. When the benefits of between-community resource access are sufficiently high, the high costs some individuals pay for maintaining these relationships (e.g., costs due to risk of aggression from other communities or navigating difficult terrain ${ }^{48}$ ) can be offset by same-community members in the form of payments ${ }^{48}$ or status. ${ }^{47}$ For example, Coast Salish men with a greater number of between-community ties were accorded more status within their communities, at least partially because these relationships provided access to nonlocal resouces. ${ }^{81}$ The importance of well-connected individuals for accessing nonlocal resources, including resources such as jobs in post-industrial nations, is echoed in the literature on weak ties in sociology. ${ }^{79}$ When the costs of between-community tolerant behavior, like threat of extra-community aggression, outweigh the benefits of nonlocal resource access, different traits should be accorded status. For example, in subsistence-scale societies in which intercommunity ties are important, well-connected individuals may be rewarded with status; when intercommunity warfare predominates, warrior-like traits may benefit same-community members and thus be rewarded with status. ${ }^{80}$ 


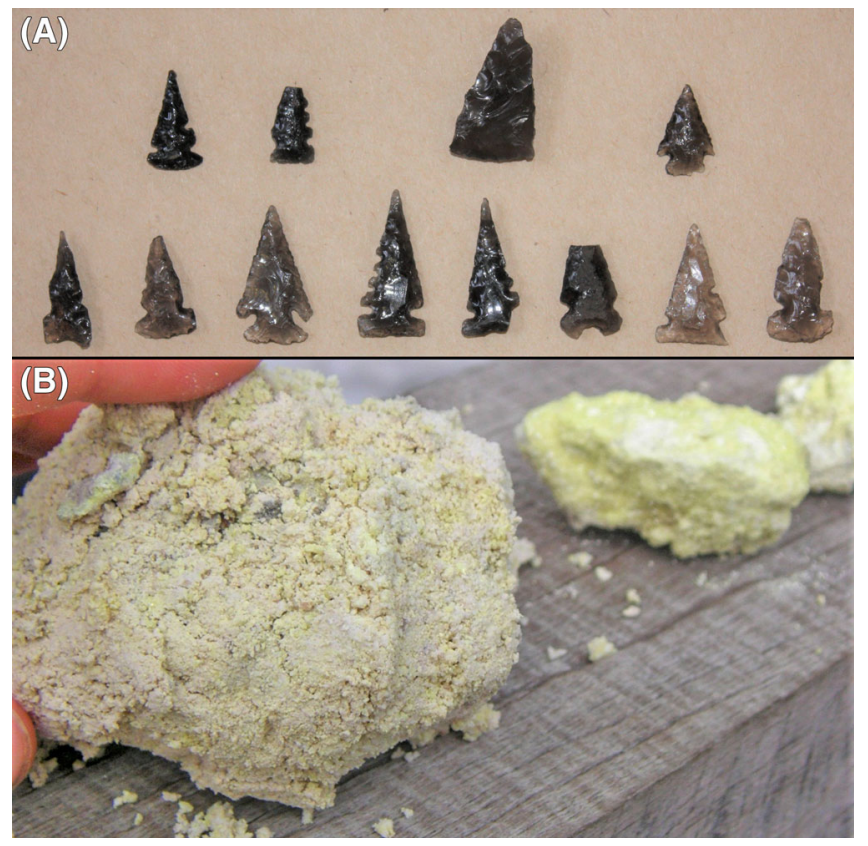

FIGURE 3 (a) Obsidian projectile points, Cibola Region, New Mexico: ca. A.D.1000-1130. Communities in the Southwest were often located at a distance from good sources of obsidian, a material from which projectile points were made --sometimes sources were a few hundred kilometers away. Some of the points pictured here were from sources 60-90 kilometers distant from the sites at which they were found. (b) In contemporary Dominica, sulfur is used by members of coastal communities to treat athlete's foot and certain fungal infections. Sulfur is collected by inland communities near volcanoes at the center of the island; individuals living in coastal communities trade for it. (a) Courtesy of Kristin Safi. (b) Courtesy of Marsha B. Quinlan [Color figure can be viewed at wileyonlinelibrary.com]

\subsection{3 | Cultural institutions}

The emergence of cultural institutions during human evolution may have further enhanced nonlocal resource access via betweencommunity relationships. Cultural institutions act as external commitment devices that enhance the reliability of extra-community partners and repurpose these relationships to additional ends. For example, inclusive fitness benefits can be amplified, even across community boundaries, by institutions that delineate appropriate behavior toward kin (and perhaps even enforce that behavior) or that foster inclusive fitness interests (e.g., through exogamous marriage). ${ }^{40}$ Fictive kinship, or ritualized relationships (e.g., as seen above among the Trobriand Islanders ${ }^{67}$ or in hxaro exchange among the $\operatorname{San}^{46}$ ), can co-opt these norms of behavior toward kin, often by enhancing feelings of social closeness, and extend them toward non-kin extra-community members. ${ }^{50,66,82}$ Norms of hospitality are similar in their mechanisms, requiring that individuals treat visiting extra-community members as they would for same-community members (see Ref. 66 for ethnographic examples). With respect to relationships based on reciprocity, research on the emergence of markets suggests that initial between-community relationships often rely on simultaneous exchange, as simultaneous exchange limits opportunities for defection. ${ }^{48,83}$ Once present, simultaneous exchange can provide the basis for between-community divisions of labor ${ }^{78}$; as seen among the Yanomamö, this specialization can not only enhance the efficiency of production but even mitigate between-community hostilities. ${ }^{58}$ If individuals do defect on betweencommunity relationships, theoretical work by economists and ethnographic data suggest that if between-community relationships are valuable enough, same-community members may punish these violations (see Ref. 84 for relevant models and ethnographic examples).

\section{3 | Studying humans: The limitations of existing research methods}

A weakness of existing theory on human intercommunity behavior in evolutionary anthropology is the paucity of data used to inform it. For example, among fieldworkers studying living humans (like A.P), our focus on local, within-community risk-buffering networks, ${ }^{49}$ the low likelihood that we observe rare events that require extra-community buffering, ${ }^{49}$ and our tendency to use only "complete" networks in social network analysis (which usually means including only same-community individuals ${ }^{85}$ ) have hindered our accurate representation of social relationships that span human community boundaries, leading researchers to often conclude that humans tend toward parochialism. To improve the accuracy of evolutionary anthropology's characterization of human intercommunity behavior, we suggest two things: that researchers attend to findings from related disciplines (such as those highlighted above) that provide evidence of the nature of the flexibility of parochialism and tolerance in humans, and that field researchers working with living humans ask about relationships that span community boundaries when collecting qualitative and quantitative data.

\section{4 | DISCUSSION}

In evolutionary anthropology and in disciplines influenced by it, a common current assumption made by researchers is a "strong human universal toward parochial altruism"-in-group favoritism at out-group cost. $^{86}$ Research focus on chimpanzees as a referential model for human behavior ${ }^{34}$ tends to promote this perspective. However, evidence suggests that individual behavior in intergroup encounters is actually quite flexible, both in humans (e.g., per the study from which the preceding quote was drawn ${ }^{86}$ ) and in the group-living great apes generally. Disincentives for intergroup aggression have been thoroughly discussed by other reviews; however, these disincentives provide insight only into when selection could favor individual tolerance toward extra-group members, but not why it does under these circumstances. Here, drawing on existing observations of nonhuman primates, we assembled potential fitness benefits that may favor intergroup tolerant encounter and association (Table 1). Though scientists know comparatively little about intergroup encounters in bonobos and gorillas relative to chimpanzees-a situation that should be remedied-the fitness benefits we identified seem to account for at least some of the observed variability in intergroup behavior in bonobos and gorillas. 
Our review of the literature suggests that the benefits favoring intergroup tolerant encounter and association in nonhuman primates can account for some, but not all, of the flexibility of intergroup tolerance in humans. In both humans and nonhuman primates, mating and transfer, as facilitated by visitation, and opportunities for social learning are potential benefits to be gained from intergroup tolerant encounter and association. Likewise, across the Primate order, kinship and partner preferences can further amplify the benefits and minimize the costs of encounter. However, humans have a much higher prevalence of intergroup tolerant encounter and association than do nonhuman primates-at least, as observed to date. Evidence from anthropology and across the social sciences suggests that humans' reliance on resources with extensive spatial and temporal variability has necessitated flexible interest in betweencommunity relationships as a means of managing the risks of resource shortfalls and ensuring access to nonlocally available resources. When and where the benefits of between-community resource access have been high, cultural institutions and social status have also enhanced and reinforced these benefits. This is not to say that humans do not engage in intergroup aggression-the ethnographic, archaeological, and contemporary records provide ample evidence of parochialism and warfare-but rather that human intergroup behavior can be both more tolerant and more aggressive than what we have observed in our closest relatives and that this flexibility in intergroup behavior is functional.

We advance the hypotheses outlined in this review for testing by the evolutionary anthropological community. Similar ideas with respect to the importance of between-community resource access have been outlined by functionalist anthropologists, archaeologists, and human behavioral ecologists previously-although usually without treatment of why between-community resource access is of particular importance in humans. We hope that by amalgamating these perspectives and building upon them, the present paper inspires newfound interest in the flexibility of human and nonhuman great ape intergroup behavior, moving our discipline beyond its current focus on parochialism. In addition to our larger hypothesis with respect to the human foraging ecology, we wish to highlight other related questions to be addressed by future work. (1) The higher the frequency of shortfalls, the more likely that individuals will recall these shortfalls (whether via their own memories or even via oral traditions) and maintain between-community relationships accordingly ${ }^{50,51}$-but how frequent must they be? Is once every several generations enough? (2) Will the connections we drew between status acquisition, cultural institutions, and the relative importance of betweencommunity resource access be supported by additional data? To date, the connection between status and between-community relationships has been more theoretical than empirical. (3) Which poses stronger selection pressure in humans: benefits gained via intergroup tolerant encounters and association in the currency of between-community resource access, or the cost of mortality risk from aggression and warfare, ${ }^{37}$ potentially reduced by intergroup tolerant encounters and association?

To answer the above questions and improve the accuracy of our characterizations of sociality in both humans and nonhuman great apes, researchers will need to collect targeted data assessing the predictors of intergroup behavior. For field researchers studying humans, we urge caution with respect to reliance on observational data and "complete" social networks. Asking participants about their social strategies for mitigating shortfalls, ${ }^{49}$ their preferences for same-community vs between-community relationships, ${ }^{41,42}$ and their extra-community ties ${ }^{85}$ may provide a more accurate picture of the flexibility of human sociality. Furthermore, the dedication of increased research effort to intergroup encounters and association in gorillas and bonobos, as well as habituation of neighboring groups, will improve our understanding of sociality in the group-living nonhuman great apes.

In the present review, we opted not to unpack the nature of human "groups" nor human group psychology. Humans are adept at cognizing groups of various kinds-from groups formed in experimental contexts to interest-based groups to ethnic or religious groupsand at recognizing their boundaries. A number of the papers and book chapters we reviewed here discuss potential derived functions of group living in humans (see Refs. 53,54,56,69). Our larger point is that human reliance on resources that vary in their spatial and temporal availability often necessitates relationships spanning distance; in general, the group-living great apes evidence flexible interest in intergroup encounters and association (Box 1), and it is likely that this flexible interest became even more important in the human lineage (Section 3.2). While relationships spanning distance sometimes span ethnolinguistic boundaries, for example, or religious boundaries, they do not necessarily. As such, questions of the proliferation of different types of human groups, and how ethnic groups may have been built on the scaffolding of social relationships through which nonlocal resources could be accessed (e.g., ${ }^{83}$ ), we leave to other papers.

Given the lack of attention the benefits of intergroup tolerant encounter and association have received in evolutionary anthropology, the present review reflects initial theorizing about these incentives; as such, we have not explored the roles of constraints, including phylogeny and life history constraints, nor the affordances of a comparative approach with non-primate species. Phylogeny and life history constraints likely affect the prevalence and flexibility of intergroup tolerance in different species of primates. For example, the relationship between intergroup tolerance and the ecological and social factors discussed here may partially reflect a third variable, phylogenetic signal. Whether such constraints explain existing observational data is a question to be answered by future work. Furthermore, we chose not to pursue a comparative approach with non-primate species. Though the high incentives for intergroup tolerant encounter and association observed in humans may have better analogies among non-primate vertebrates or even insects, ${ }^{2}$ our goal here was to explore intergroup tolerance in humans in the context of nonhuman primates rather than to find the closest-match analogy for human behavior.

\section{5 | CONCLUSION}

Intergroup behavior in primates is flexible, and the prevalence of intergroup tolerant encounters and association varies across species. To be sure, incentives for aggression vary, as discussed extensively in existing work; however, when incentives for aggression are low or absent, why would natural selection favor tolerant behavior toward extra-group members-or even increased rates of intergroup tolerant encounter and association? Drawing inferences from the existing primatological 
literature, we highlighted benefits favoring intergroup tolerant encounter and association in the Primate order, including in group-living nonhuman apes and humans, such as transfer, mating, and food acquisition. Humans are unique among primates in our high prevalence of intergroup tolerance, however, and data from across the social sciences suggest the relevance of the human foraging ecology-especially the spatial and temporal availability of resources on which we depend-in explaining the human pattern. Future research should work to better document the variability in intergroup behavior in the group-living apes, especially in gorillas, bonobos, and humans, using methods of data collection designed specifically for this endeavor.

\section{ACKNOWLEDGMENTS}

We thank Monique Borgerhoff Mulder, Andrew Duff, Michael Gurven, Edward Hagen, Daniel Hruschka, James Holland Jones, Dieter Lukas, Peter Richerson, and Rustam Romaniuc for helpful discussion. Thanks to John Bunce, Adrian Jaeggi, Benjamin Purzycki, and the Departments of Primatology and Human Behavior, Ecology, and Culture, Max Planck Institute for Evolutionary Anthropology, for comments on earlier versions of the manuscript.

\section{GLOSSARY}

Association: Upon encounter, two conspecifics remain in spatial proximity to one another.

Community: For the purposes of this article, we define communities as human individuals living in close spatial proximity. While "community" is sometimes used to describe bonobo and chimpanzee groups given their fission-fusion dynamics, ${ }^{54}$ in our experience this causes confusion among primate researchers; as such, we use the word "community" only in reference to humans to avoid the ambiguity of the word "group," which has a multitude of meanings in the human literature. Members of the same community are referred to as "samecommunity" and members of other communities as "extra-community."

Contest: An aggressive interaction between two conspecifics over access to a resource.

Dear Enemy Effect: When an individual responds more aggressively to a territorial incursion from a stranger than to an incursion from an individual with a neighboring territory. ${ }^{16}$

Encounter: Visual or vocal contact between two conspecifics. When possible, we recommend researchers study visual, rather than vocal, encounters when studying intergroup encounter for two reasons. First, vocal encounters do not differentiate between the strategies outlined in Figure 1. For example, individuals may use long calls to signal their group's position to extra-group conspecifics either to facilitate or avoid encounter ${ }^{5}$-vocal encounters do not allow us to disambiguate these potential explanations. Second, from a logistical perspective, it can be difficult for field researchers to distinguish same-group from intergroup encounters in societies with fissionfusion dynamics, where parties may be foraging separately, unless they witness these encounters. Because of these limitations, visual encounters are preferable sources of data.
Fission-fusion dynamics: A feature of some primate societies in which groups split into smaller parties (see Ref. 21 for discussion).

Group: In the Primate order, groups are individuals "which remain [physically] together in or separate from a larger unit" and interact with each other more than with other individuals. ${ }^{6}$ This definition does not cover all uses of the word "group" in the social sciences (e.g., human identity groups who identify with a common name or symbol may or may not interact with one another more frequently than with other individuals). Because of this ambiguity, we use the word "community" when referring to humans to better capture the notion of spatial proximity, per Ref. 54. Members of the same group are referred to as "same-group" and those from another group "extra-group."

Intergroup encounter: An encounter between at least two members from each of two groups. An encounter in which only one individual from each group participates is often called a "temporal visit."

Interspecific association: An association between individuals from two or more species.

Multilevel society: Social organization in which basal units (often, but not always, reproductive units and/or bachelor groups of males) are parts of larger groups.

Party: An ephemeral association of conspecifics which does not meet the definition of a group. ${ }^{21}$

Tolerance: An individual has an encounter with a conspecific and can freely leave but remains in the encounter without acting aggressively toward the conspecific. See Figure 1.

\section{ORCID}

Anne C. Pisor (DD https://orcid.org/0000-0001-5780-4542

\section{REFERENCES}

[1] Grueter CC, White DR. 2014. On the emergence of large-scale human social integration and its antecedents in primates. Struct Dyn eJournal Anthropol Relat Sci 7:1-27.

[2] Robinson EJH, Barker JL. 2017. Inter-group cooperation in humans and other animals. Biol Lett 13:20160793.

[3] Jaeggi AV, Boose KJ, White FJ, et al. 2016. Obstacles and catalysts of cooperation in humans, bonobos, and chimpanzees: behavioural reaction norms can help explain variation in sex roles, inequality, war and peace. Behaviour 153:1015-1051.

[4] Brewer MB, Campbell DT. 1976. Ethnocentrism and intergroup attitudes: East African evidence, Oxford: Sage.

[5] Cheney D. 1987. Interactions and relationships between groups. In: Smuts BB, editor. Primate societies, Chicago: University of Chicago Press. p 267-281.

[6] Kummer H. 1971. Primate societies: group techniques of ecological adaptation, London: Routledge.

[7] Kappeler PM, van Schaik CP. 2002. Evolution of primate social systems. Int J Primatol 23:707-740.

[8] Dyson-Hudson R, Smith EA. 1978. Human territoriality: an ecological reassessment. Am Anthropol 80:21-41.

[9] Maher CR, Lott DF. 2000. A review of ecological determinants of territoriality within vertebrate species. Am Midl Nat 143:1-29.

[10] Brown M. 2013. Food and range defence in group-living primates. Anim Behav Elsevier Ltd. 85:807-816.

[11] van Schaik CP. 1989. The ecology of social relationships amongst female primates. In: Standen V, Foley RA, editors. Comparative 
socioecology: the behavioral ecology of humans and other mammals. Oxford: Blackwell Science Ltd. p 195-218.

[12] Borgerhoff Mulder M, Schacht R. 2012. Human behavioural ecology. In: eLS. Chichester: John Wiley \& Sons, Ltd. https://doi.org/10. 1002/9780470015902.a0003671.pub2

[13] Clutton-Brock T, Janson C. 2012. Primate socioecology at the crossroads: past, present, and future. Evol Anthropol 21:136-150.

[14] Jones JH. 2011. Primates and the evolution of long, slow life histories. Curr Biol Elsevier Ltd. 21:R708-R717.

[15] Kitchen D, Beehner J. 2007. Factors affecting individual participation in group-level aggression among non-human primates. Behaviour 144:1551-1581.

[16] Christensen C, Radford AN. 2018. Dear enemies or nasty neighbors? Causes and consequences of variation in the responses of groupliving species to territorial intrusions. Behav Ecol 29:1004-1013.

[17] Waser PM. 1980. Polyspecific associations of Cercocebus albigena: geographic variation and ecological correlates. Folia Primatol 33: 57-76.

[18] Glowacki L, Wilson ML, Wrangham RW. 2017. The evolutionary anthropology of war. J Econ Behav Organ. https://doi.org/10.1016/ j.jebo.2017.09.014

[19] Kirkpatrick RC, Grueter CC. 2010. Snub-nosed monkeys: multilevel societies across varied environments. Evol Anthropol 19:98-113.

[20] Schreier AL, Swedell L. 2009. The fourth level of social structure in a multi-level society: ecological and social functions of clans in Hamadryas Baboons. Am J Primatol 71:948-955.

[21] Grueter CC, Chapais B, Zinner D. 2012. Evolution of multilevel social systems in nonhuman primates and humans. Int J Primatol 33: 1002-1037.

[22] Heymann EW, Buchanan-Smith HM. 2000. The behavioural ecology of mixed-species troops of callitrichine primates. Biol Rev 75: 169-190.

[23] Henzi P, Barrett L. 2003. Evolutionary ecology, sexual conflict, and behavioral differentiation among baboon populations. Evol Anthropol 12:217-230.

[24] Kirkpatrick RC, Long YC, Zhong T, et al. 1998. Social organization and range use in the Yunnan snub-nosed monkey Rhinopithecus bieti. Int J Primatol 19:13-51.

[25] Prescott MJ, Buchanan-Smith HM. 1999. Intra- and inter-specific social learning of a novel food task in two species of tamarin. Int $J$ Comp Psychol 12:71-92.

[26] Sauther ML. 1991. Reproductive behavior of free-ranging Lemur catta at Beza Mahafaly Special Reserve, Madagascar. Am J Phys Anthropol 84:463-477.

[27] Cheney D, Seyfarth R. 1982. Recognition of individuals within and between groups of free ranging vervets. Am Zool 22:519-529.

[28] Boesch C, Crockford C, Herbinger I, et al. 2008. Intergroup conflicts among chimpanzees in Taï National Park: lethal violence and the female perspective. Am J Primatol 70:519-532.

[29] Sakamaki T et al. 2015. Intergroup transfer of females and social relationships between immigrants and residents in bonobo (Pan paniscus) societies. In: Furuichi $\mathrm{T}$ et al., editors. Dispersing primate females, Japan: Springer. p 127-164.

[30] Forcina G, Vallet D, le Gouar PJ, et al. 2019. From groups to communities in western lowland gorillas. Proc R Soc B Biol Sci 286: 20182019.

[31] Sicotte P. 1993. Inter-group encounters and female transfer in mountain gorillas: influence of group composition on male behavior. Am J Primatol 30:21-36.

[32] Ishizuka S, Kawamoto Y, Sakamaki T, et al. 2018. Paternity and kin structure among neighbouring groups in wild bonobos at Wamba. $\mathrm{R}$ Soc Open Sci 5:171006.

[33] Bartlett TQ. 2003. Intragroup and intergroup social interactions in white-handed gibbons. Int J Primatol 24:239-259.
[34] Wrangham RW. 1999. Evolution of coalitionary killing. Yearb Phys Anthropol 42:1-30.

[35] Wrangham RW, Glowacki L. 2012. Intergroup aggression in chimpanzees and war in nomadic hunter-gatherers: evaluating the chimpanzee model. Hum Nat 23:5-29.

[36] van Schaik CP. 2016. The primate origins of human nature, Hoboken, NJ: Wiley Blackwell.

[37] Fry DP. 2018. The evolutionary logic of human peaceful behavior. In: Verbeek P, Peters BA, editors. Peace ethology: behavioral processes and systems of peace, Hoboken, NJ: Wiley Blackwell. p 249-265.

[38] Parish AR, De Waal FBM. 2000. The other "Closest Living Relative": how bonobos (Pan paniscus) challenge traditional assumptions about females, dominance, intra- and intersexual interactions, and hominid evolution. Ann N Y Acad Sci 4:97-113.

[39] Foley R, Gamble C. 2009. The ecology of social transitions in human evolution. Philos Trans R Soc Lond B Biol Sci 364:3267-3279.

[40] Chapais B. 2008. Primeval kinship: how pair-bonding gave birth to human society, Cambridge, MA: Harvard University Press.

[41] Pisor AC, Gurven M. 2018. When to diversify, and with whom? Choosing partners among out-group strangers in lowland Bolivia. Evol Hum Behav 39:30-39.

[42] Pisor AC, Gurven M. 2016. Risk buffering and resource access shape valuation of out-group strangers. Sci Rep 6:30435.

[43] Cashdan E. 1983. Territoriality among human foragers: ecological models and an application to four bushman groups. Curr Anthropol 24: 47-66.

[44] Kelly RL. 1995. The foraging spectrum: diversity in hunter-gatherer lifeways, Washington, D.C.: Smithsonian Institution Press.

[45] Smith EA. 1988. Risk and uncertainty in the "original affluent society": evolutionary ecology of resource-sharing and land tenure. In: Ingold T et al., editors. Hunters and gatherers Vol I: history, evolution and social change, Oxford: Berg Publishers. p 222-252.

[46] Wiessner P. 1982. Risk, reciprocity and social influences on !Kung San economics. In: Politics and history in band societies, New York, NY: Cambridge University Press. p 61-84.

[47] Braun DP, Plog S. 1982. Evolution of "tribal" social networks: theory and prehistoric North American evidence. Am Antiq 47:504-525.

[48] Fitzhugh B et al. 2011. Modeling hunter-gatherer information networks: an archaeological case study from the Kuril Islands. In: Whallon $R$ et al., editors. Information and its role in hunter-gatherer bands, Los Angeles, CA: The Costen Institute of Archaeology. p 85-115.

[49] Wobst HM. 1978. The archaeo-ethnology of hunter-gatherers or the tyranny of the ethnographic record in archaeology. Am Antiq 43:303-309.

[50] Minnis PE. 1985. Social adaptation to food stress: a prehistoric southwestern example, Chicago: University of Chicago Press.

[51] Halstead P, O'Shea J. 1989. Introduction: Cultural responses to risk and uncertainty. In: Halstead P, O'Shea J, editors. Bad year economics: cultural responses to risk uncertainity, Cambridge, UK: Cambridge University Press. p 1-7.

[52] Spielmann KA. 1986. Interdependence among egalitarian societies. J Anthropol Archaeol 5:279-312.

[53] Brewer MB, Caporeal LR. 2006. An evolutionary perspective of social identity: revisiting groups. In: Schaller $M$ et al., editors. Evolution and social psychology, Madison, CT: Psychosocial Press. p 143-161.

[54] Rodseth L, Wrangham RW, Harrigan AM, et al. 1991. The human community as a primate society. Curr Anthropol 32:221-254.

[55] Geertz C. 2018. The bazaar economy: information and search in peasant marketing. In: Granovetter M, Swedberg R, editors. The sociology of economic life, New York, NY: Routledge. p 594.

[56] Henrich J. 2015. The secret of our success: how culture is driving human evolution, domesticating our species, and making us smarter, Princeton, NJ: Princeton University Press. 
[57] Sniderman PM, Hagendoorn L, Prior M. 2004. Predisposing factors and situational triggers: exclusionary reactions to immigrant minorities. Am Polit Sci Rev 98:35-49.

[58] Chagnon NA. 1992. Yanomamo, Fort Worth, TX: Harcourt Brace Jovanovich College Publishers.

[59] Barnes R. 1999. Marriage by capture. J R Anthropol Inst 5:57-73.

[60] Sugawara K. 1988. Visiting relations and social interactions between residential groups of the Central Kalahari San: hunter-gatherer camp as a micro-territory. Afr Study Monogr 8:173-211.

[61] Cashdan E, Kramer KL, Davis HE, et al. 2016. Mobility and navigation among the Yucatec Maya: sex differences reflect parental investment, not mating competition. Hum Nat 27:35-50.

[62] Williams AM, Hall CM. 2000. Tourism and migration: new relationships between production and consumption. Tour Geogr 2:5-27.

[63] Buchan NR, Grimalda G, Wilson R, et al. 2009. Globalization and human cooperation. Proc Natl Acad Sci U S A 106:4138-4142.

[64] MacDonald DH, Hewlett BS. 1999. Reproductive interests and forager mobility. Curr Anthropol 40:501-524.

[65] Hollingshead AB. 1950. Cultural factors in the selection of marriage mates. Am Sociol Rev 15:619-627.

[66] Sahlins M. 1972. Stone age economics, New York, NY: Routledge Chapman Hall.

[67] Malinowski B. 1922. Argonauts of the Western Pacific, London: Routledge and Keegan Paul.

[68] Radcliffe-Brown AR. 1922. The Andaman Islanders, Cambridge, UK: Cambridge University Press.

[69] Kaplan H, Hill K, Lancaster J, et al. 2000. A theory of human life history evolution: diet, intelligence, and longevity. Evol Anthropol Issues, News, Rev 9:156-185.

[70] Pontzer H, Brown MH, Raichlen DA, et al. 2016. Metabolic acceleration and the evolution of human brain size and life history. Nature Nature Publishing Group. 533:390-392.

[71] Leonard WR, Snodgrass JJ, Robertson ML. 2007. Effects of brain evolution on human nutrition and metabolism. Annu Rev Nutr 27: 311-327.

[72] Hockett B, Haws J. 2003. Nutritional ecology and diachronic trends in paleolithic diet and health. Evol Anthropol 12:211-216.

[73] Cunnane SC, Crawford MA. 2014. Energetic and nutritional constraints on infant brain development: implications for brain expansion during human evolution. J Hum Evol Elsevier Ltd. 77:88-98.

[74] Yengoyan AA. 1968. Demographic and ecological influences on Aboriginal Australian marriage sections. In: Lee RB, DeVore I, editors. Man the hunt, Chicago: Aldine Publishing Company. p 185-199.

[75] Colson E. 1979. In good years and in bad: food strategies of selfreliant societies. J Anthropol Res 35:18-29.

[76] Pelling M. 2002. Assessing urban vulnerability and social adaptation to risk: evidence from Santo Domingo. Idpr 24:59-76.

[77] Lathrap DW. 1973. The antiquity and importance of long-distance trade relationships in the moist tropics of Pre-Columbian South America. World Archaeol 5:170-186.

[78] Demps K, Winterhalder B. 2018. "Every tradesman must also be a merchant": behavioral ecology and household-level production for barter and trade in premodern economies. J Archaeol Res Springer US. 27:49-90.

[79] Granovetter MS. 1973. The strength of weak ties. Am J Sociol 78 : 1360-1380.

[80] von Rueden C. 2014. The roots and fruits of social status in smallscale human societies. In: Cheng JT et al., editors. The psychology of social status, New York: Springer. p 179-200.

[81] Elmendorf WW. 1971. Coast Salish status ranking and intergroup ties. Southwest J Anthropol 27:353-380.

[82] Hruschka DJ. 2010. Friendship: development, ecology, and evolution of a relationship, Berkeley, CA: University of California Press.

[83] Barth F. 1969. Ethnic groups and boundaries: the social organization of culture difference, Long Grove, IL: Waveland Press.
[84] Fearon JD, Laitin DD. 1996. Explaining interethnic cooperation. Am Polit Sci Rev 90:715-735.

[85] Ready E et al. 2018. Addressing the challenges of missing data in anthropological networks. Am. Assoc. Phys. Anthropol 165:221.

[86] Romano A, Balliet D, Yamagishi T, et al. 2017. Parochial trust and cooperation across 17 societies. Proc Natl Acad Sci 114:12702-12707.

[87] Hohmann G. 2001. Association and social interactions between strangers and residents in bonobos (Pan paniscus). Primates 42:91-99.

[88] Schubert G, Stoneking CJ, Arandjelovic M, et al. 2011. Malemediated gene flow in patrilocal primates. PLoS One 6:e21514.

[89] Lucchesi S, Cheng L, Janmaat $K$, et al. Interacting beyond the group: how food, mates and group size influence associations between communities in wild bonobos.

[90] Fruth B, Hohmann G. 2018. Food sharing across borders. Hum Nat 29:91-103

[91] Surbeck M, Langergraber KE, Fruth B, et al. 2017. Male reproductive skew is higher in bonobos than chimpanzees. Curr Biol 27: R640-R641.

[92] Tokuyama N, Furuichi T. 2017. Leadership of old females in collective departures in wild bonobos (Pan paniscus) at Wamba. Behav Ecol Sociobiol 71:55.

[93] Mirville MO, Ridley AR, Samedi JPM, et al. 2018. Factors influencing individual participation during intergroup interactions in mountain gorillas. Anim Behav Elsevier Ltd. 144:75-86.

[94] Parnell RJ. 2002. The social structure and behaviour of western lowland gorillas (Gorilla gorilla gorilla) at Mbeli Bai, University of Stirling: Republic of Congo.

[95] Caillaud D, Ndagijimana F, Giarrusso AJ, et al. 2014. Mountain gorilla ranging patterns: influence of group size and group dynamics. Am J Primatol 76:730-746.

[96] Inoue E, Akomo-Okoue EF, Ando C, et al. 2013. Male genetic structure and paternity in western lowland gorillas (Gorilla gorilla gorilla). Am J Phys Anthropol 151:583-588.

[97] Herbinger I, Boesch C, Rothe H. 2001. Territory characteristics among three neighboring chimpanzee communities in the Tai National Park, Côte d'Ivoire. Int J Primatol 22:143-167.

[98] Waller MT. 2011. The ranging behavior of bonobos in the Lomako Forest, Eugene, OR: University of Oregon.

[99] Bermejo M. 2004. Home-range use and intergroup encounters in western gorillas (Gorilla G. gorilla) at Lossi forest, North Congo. Am J Primatol 64:223-232.

[100] Wilson ML, Wrangham RW. 2003. Intergroup relations in chimpanzees. Annu Rev Anthropol 32:363-392.

[101] Rosenbaum S, Vecellio V, Stoinski T. 2016. Observations of severe and lethal coalitionary attacks in wild mountain gorillas. Sci Rep 6: 37018.

[102] Watts DP, Mitani JC. 2000. Boundary patrols and intergroup encounters in wild chimpanzees. Behaviour 138:299-327.

[103] Sakamaki T, Ryu H, Toda K, et al. 2018. Increased frequency of intergroup encounters in wild bonobos (Pan paniscus) around the yearly peak in fruit abundance at Wamba. Int J Primatol 39:685-704.

[104] Furuichi T. 2011. Female contributions to the peaceful nature of bonobo society. Evol Anthropol 20:131-142.

\section{AUTHOR BIOGRAPHIES}

Anne Pisor is an assistant professor in the Department of Anthropology at Washington State University. She studies the origins, maintenance, and flexibility of between-community relationships in humans, including flexibility in these relationships among three populations of Bolivian horticulturalists as their market participation, mobility, and access to communications networks increases. 
Martin Surbeck is an assistant professor in the Department of Human Evolutionary Biology at Harvard University and director of the Kokolopori Bonobo Research Project. His research examines the link between the ecology, social structure, reproductive strategies, and cooperation in the species of the genus Pan.
How to cite this article: Pisor AC, Surbeck M. The evolution of intergroup tolerance in nonhuman primates and humans. Evolutionary Anthropology. 2019;28:210-223. https://doi.org/ 10.1002/evan.21793 